Research Paper

\title{
Detection of multi drug resistant bacteria in major hospitals in Kano, North-West, Nigeria
}

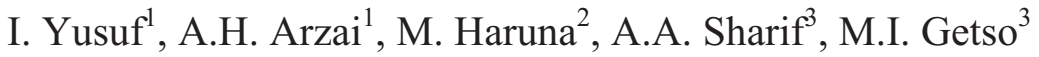 \\ ${ }^{1}$ Department of Microbiology, Faculty of Science, Bayero University, Kano, Nigeria. \\ ${ }^{2}$ Department of Biology, Kano University of Science and Technology, Wudil, Kano, Nigeria. \\ ${ }^{3}$ Department of Microbiology and Parasitology, Faculty of Medicine, Bayero University, Kano, Nigeria.
}

Submitted: January 26, 2013; Approved: March 14, 2014.

\begin{abstract}
Two major hospitals in Kano, North West Nigeria have recorded increasing resistance of clinical pathogens to broad spectrum $\beta$ lactams, mediated by extended spectrum $\beta$ - lactamase (ES $\beta$ L) and non ESBLs. A study was therefore undertaken to determine the occurrence and prevalence of plasmid and chromosomal mediated AmpC $\beta \mathrm{L}$ and carbapenemase in addition to already known ESBL due to increasing resistance of pathogens from the two hospitals to carbapenems, cephamycins and flouroquinolones. Antibiogram tests and ESBL, AmpC and carbapenemase production tests were performed on all the isolates. AmpC and carbapenemase producers were further screened for AmpC inducibility and metallo beta lactamase production respectively. Majority of the isolates (> $80 \%$ ) were resistant to both $\beta$-lactam and non $\beta$-lactam antibiotics. Reduced susceptibility to levofloxacin, nitrofurantoin, nalidixic acid and ofloxacin among the isolates were observed with the exception of $P$. aeruginosa which is totally resistant to imipenem and levofloxacin. An overall prevalence of $14.4 \%, 11.9 \%$ and $11.9 .3 \%$ for ES $\beta \mathrm{L}, \mathrm{AmpC}$ and carbapenemase was observed respectively. About $7.9 \%$ of the AmpC producers can over expressed the chromosomally mediated AmpC and $85.8 \%$ of the carbapenemase producers require metal for their action. Co-production of either of two and/or all of the enzymes was observed in E. coli, P. mirabilis and P. aeruginosa. Antibiotic resistance among isolates from the two hospitals is increasing and the major cause of this resistance in the pathogens studied are production of $\mathrm{AmpC}$, carbapenemase (especially Metallo $\beta$ - lactamase) in addition to already known ESBL enzymes by the pathogens. Some of the isolates also possess the capacity to elaborate two or more of the enzymes concurrently, which would renders them resistant to a multitude of antibiotics.
\end{abstract}

Key words: AmpC $\beta$-lactamases, extended spectrum $\beta$-lactamases, coexistence, prevalence, Gram negative bacteria.

\section{Introduction}

$\beta$-lactamases are enzymes produced by some bacteria and are responsible for their resistance to $\beta$-lactam antibiotics like penicillins, cephamycin and carbapenem (Bush et $a l .$, 1995). $\beta$-lactamase deactivates the molecular antibacterial properties of $\beta$-lactam antibiotics there by breaking and opening the common element in their molecular structure $\beta$-lactam (Bush et al., 1995). Some of these enzymes in- clude extended spectrum $\beta$-lactamase (ESBL), AmpC $\beta \mathrm{L}$, and carbapenemase.

ESBLs are plasmid-mediated $\beta$-lactamase that are capable of efficiently hydrolyzing penicillin, narrow and broad spectrum cephalosporins and monobactams (Aztreonam), but they do not hydrolyze cephamycin or carbapenems (imipenem, meropenem) (Emery and Weymouth, 1997). $\beta$-Lactamase, inhibitors such as clavulanic acid, sulbactam and tazobactam generally inhibit ESBL produc-

Send correspondence to I. Yusuf. Department of Microbiology, Faculty of Science, Bayero University, P.M.B. 3011, Kano, Nigeria. E-mail: yusufi4730@buk.edu.ng. 
ing strains (Naumorskil and Palzkill, 1999). ESBL producing isolates are most commonly found in Klebsiella pneumoniae and Escherichia coli (Winokur and Brueggemann-Desalvo, 2005).

AmpC $\beta$-lactamase is primarily chromosomal and plasmid-mediated and are resistant to $\beta$-lactamase inhibitors such as clavulanic acid but can hydrolyze cephamycin (Livermore and Woodford, 2000). Carbapenems are one of the antibiotics of last resort for many bacterial infections such as E. coli and K. pneumoniae producing AmpC and extended spectrum $\beta$-lactamase but the emergence of carbapenemase which have versatile hydrolytic capacities have the ability to hydrolise pencillins, cephalosporins, monobactams and carbapenems (Fernando et al., 2009).

Infection caused by organisms producing such enzymes have resulted in poor outcomes, reduced rate of clinical and microbiological responses, longer hospital stays and greater hospital expenses (Paterson et al., 2004). Physical contact is the most likely mode of transmission and the gastrointestinal tract of colonized or infected patients is the most frequent reservoir while transient carriage of bacteria on the hands of healthcare workers may lead to transmission to patients (Paterson et al., 2004).

The spread of these resistant bacteria in hospitals all over the world, conferring multiple antibiotic resistances in the treatment and management of life threatening infections necessitate this study. The routine susceptibility tests performed by clinical laboratories in Nigeria, fail to detect bacteria harboring these enzymes, which have led to inappropriate and unsuccessful therapy of patient and unnecessary use of drugs. This study was therefore aimed at determining the antibiotic susceptibility of the commonly isolated pathogens in Aminu Kano Teaching Hospital, Kano (AKTH) and Murtala Muhammad Specialist Hospital, Kano (MMSH), North-west Nigeria to commonly prescribed antibiotics and relates the gross antibiotic resistance to production of AmpC, carbapenemase and ESBL and their co-production in different isolates.

\section{Materials and Methods}

\section{Collection of clinical isolates}

A total of six hundred and thirty three (633) consecutive non repetitive Gram negative clinical bacterial isolates derived from samples of urine, catheter tips, stool, semen, urogenitals, and abscesses were collected from pathology department of AKTH and MMSH over a period of 12 months. The isolates included E. coli (278), Klebsiella pneumoniae (128), Proteus mirabilis (89), P. vulgaris (32), Pseudomonas aeruginosa (83), Salmonella typhi (4), Serratia mercesens (1), Morganella spp (2) and Enterobacter spp (16). Isolates were obtained from both outpatients and inpatients. However, attention were given to 17 isolates from inpatients admitted into intensive care unit (ICU) and Special Care Baby Unit (SCBU) which in- cluded 7 E. coli, 4 K. pneumoniae, 1 P. mirabilis and 5 P. aeruginosa that were totally resistant to all the antibiotics tested against them in the laboratory.

\section{Antimicrobial susceptibility testing}

An antibiotic susceptibility test was performed on all the isolates by disc diffusion method (CLSI, 2005). The zone diameters of each of the antibiotics were interpreted as per Clinical Laboratory Standards Institute (CLSI) recommendations (CLSI, 2005). Sixteen different antibiotic discs commonly prescribed by clinicians in the two hospitals except cefoxitin were used. These included: gentamicin $(10 \mu \mathrm{g})$, co-trimoxazole $(25 \mu \mathrm{g})$, ciprofloxacin $(5 \mu \mathrm{g})$, cefpodoxime $(30 \mu \mathrm{g})$, ceftazidime $(30 \mu \mathrm{g})$, ceftriaxone $(30 \mu \mathrm{g})$, cefoxitin $(30 \mu \mathrm{g})$, imipenem $(10 \mu \mathrm{g})$, nalidixic acid $(30 \mu \mathrm{g})$, amoxycillin $(20 \mu \mathrm{g})$, ofloxacin $(30 \mu \mathrm{g})$, levofloxacin $(30 \mu \mathrm{g})$, nitrofurantoin $(300 \mu \mathrm{g})$, tetracycline $(30 \mu \mathrm{g})$, chlorampenicol $(30 \mu \mathrm{g})$ and augmentin $(30 \mu \mathrm{g})$ (Oxoid, UK). Escherichia coli ATCC 25922 strain was used as a control culture.

\section{Beta lactamase detection, presumptive and confirmatory test for ESBL}

The types of $\beta$-lactamase produced by the clinical isolates were investigated by phenotypic based methods.

All the clinical isolates collected were tested for potential ESBL producers using the cefpodoxime $(10 \mu \mathrm{g})$ ceftazidime $(30 \mu \mathrm{g})$ and the ceftriaxone $(30 \mu \mathrm{g})$ antibiotic discs (Oxoid, UK). Results were interpreted based on the CLSI criteria (CLSI, 2005). Organisms showing a zone of inhibition of $\leq 21 \mathrm{~mm}$ to cefpodoxime or $\leq 20 \mathrm{~mm}$ to ceftazidime and ceftriaxone were subjected to confirmatory test using the double discs synergy test as described by CLSI guidelines (CLSI, 2005). In the method, a suspension of the test organism was inoculated on Mueller- Hinton agar (MHA) (Oxoid, UK). A disc containing $30 \mu \mathrm{g}$ amoxicillin plus clavulanic acid was placed centrally on the plate. Discs containing cefpodoxime $(10 \mu g)$ and ceftriaxone $(30 \mu \mathrm{g})$ were placed on the agar at a distance of $15 \mathrm{~mm}$ from the amoxicillin + clavulanic acid disk. The plates were incubated over night at $35^{\circ} \mathrm{C}$. A $\geq 5 \mathrm{~mm}$ increase in zone diameter for either antimicrobial agent combination compared to its zone when tested alone signified a positive ESBL.

\section{AmpC screening and confirmatory test}

The susceptibility of the isolates to cefoxitin disc $30 \mu \mathrm{g}$ (Oxoid, UK) was determined and all isolates that yielded a zone diameter less than $18 \mathrm{~mm}$ were tested for AmpC enzyme production by AmpC disk test according to the method of Black et al. (2005).

In brief, $0.5 \mathrm{McFarland}$ suspension of ATCC E. coli 25922 was inoculated on the surface of a MHA (Oxoid, 
UK) plate. A $30 \mu$ g cefoxitin (Oxoid, UK) disc was placed on the inoculated surface of the agar. A sterile plain disc inoculated with 2-3 pure colonies of the test organism was placed beside the cefoxitin disc $2 \mathrm{~mm}$ away from the edge, with the inoculated disk face in contact with the agar surface. The plates were incubated at $37^{\circ} \mathrm{C}$ for $24 \mathrm{~h}$. After incubation, the plates were examined for either an indentation or a flattening of the zone of inhibition, indicating enzymatic inactivation of cefoxitin (positive result), or the absence of a distortion, indicating no significant inactivation of cefoxitin (negative result).

\section{Detection of inducible AmpC production (Disc antagonism test)}

Screening for the inducible AmpC $\beta$-lactamase was done by the method of Sanders et al. (1996). This was done by placing cefoxitin disc (Oxoid, UK) at a distance of 20 mm from ceftazidime (Oxoid, UK) on the surface of MHA inoculated with the test organism. $\beta$-lactamase inducibility was recognized by blunting of the ceftazidime (Oxoid, UK) zone adjacent to cefoxitin (Oxoid, UK).

\section{Screening and confirmatory test for carbapenemase}

The bacterial isolates were screened for carbapenemase production according to CLSI guidelines (CLSI, 2005). In this method, carbapenem antibiotics-meropenem (MEM) and imipenem (IPM) discs (10 $\mu \mathrm{g}$, each) (Oxoid, UK) were used. The antibiotic discs were placed on the surface of MHA plates using sterile forceps. The discs were placed about $30 \mathrm{~mm}$ apart and the plates were incubated for $24 \mathrm{~h}$ at $37^{\circ} \mathrm{C}$ after which zones of inhibitions were read. Isolates that showed a zone of inhibition $\leq 21 \mathrm{~mm}$ in diameter for meropenem were considered as suspected carbapenemase producers and were subjected to confirmatory test by the Modified Hodges Test (MHT).

\section{Modified hodges test}

A Mcfarland suspension of E. coli ATCC 25922 was streaked with a sterile cotton swab on surface of MHA plates. Two discs of meropenem and imipenem $(10 \mu \mathrm{g})$ were placed on the surface of MHA $30 \mathrm{~mm}$ apart lying diagonally opposite to each other. In a straight line, by means of a sterilized wire loop, the test organisms were streaked from the edge of one disc meropenem to edge of the other imipenem disc. Up to four organisms were tested on the same MHA plate. The plates were incubated at $37^{\circ} \mathrm{C}$ for $24 \mathrm{~h}$.

They were examined for a clover leaf type indentation or flattening at the intersection of the test organism and $E$. coli ATCC 25922 within the zone of inhibition of the carbapenem susceptibility disc as described by Anderson et al. (2007).

\section{Screening of carbapenemase producers for Metallo $\beta$-Lactamases (MBLs)}

EDTA-disc synergy test was used as described by Walsh et al. (2005) and CLSI, (2005). A carbapenemase producing isolate was streaked on the surface of the MHA using a sterile wire loop. Two meropenem discs, one containing EDTA and the other without EDTA were placed on the surface of the MHA using a sterile forceps at a distance of about $30 \mathrm{~mm}$ apart. The EDTA disc was prepared by adding $250 \mu \mathrm{L}$ of neutral EDTA to MEM. The plates were incubated for $24 \mathrm{~h}$ at $37^{\circ} \mathrm{C}$. Zones of inhibition were recorded after $24 \mathrm{~h}$ of incubation. Control disc containing EDTA alone was used to determine the activity of the EDTA to ensure that it does not cause false-positive results by inhibiting the test isolate. Organisms that showed difference in diameter of zone of inhibition by $\geq 4 \mathrm{~mm}$ on the MEM containing EDTA and MEM alone is confirmed for the production of MBLs.

\section{Results}

\section{Antimicrobial susceptibility testing}

Antibacterial susceptibility of clinical isolates from the two hospitals to the commonly prescribed antibiotics in the hospitals showed that majority of the isolates were resistant to $\beta$-lactam antibiotics such amoxicillin, augmentin, cefpodoxime, ceftriaxone and non $\beta$ lactam antibiotics such as chlorampenicol, co-trimoxazole and tetracycline. Majority of the isolates showed reduced susceptibility to levofloxacin, nitrofurantoin, nalidixic acid and ofloxacin with the exception of $P$. aeruginosa which is totally resistant to imipenem and levofloxacin but showed enhanced sensitivity to cefoxitin (Table 1).

\section{ESBL, AmpC and carbapenemase producing isolates}

Out of the 633 isolates screened for ESBL production, 91 were confirmed to produce ESBL giving an overall prevalence of $14.4 \%$. The highest prevalence of ESBLs was found in Enterobacter spp (31.3\%), followed by E. coli (17\%), K. pneumoniae (14.8\%), P. mirabilis (13.5\%) P. vulgaris $(6.3 \%)$ and Ps. aeruginosa had the least ESBL prevalence of $4.8 \%$ (Table 2). No ESBL production was detected in Serratia mercenses but one out of the two $M$. morganii produces ESBL.

The susceptibility of the isolates to cefoxitin disc showed that 291 isolates equivalent to $(46.3 \%)$ were found to be either resistant or showed reduced susceptibility to cefoxitin while 342 (54\%) were susceptible (Table 3). The overall prevalence of AmpC $\beta$-lactamases was $11.9 \%$. Similar to ESBL, Enterobacter spp had the highest prevalence of (18.8\%), followed by Ps. aeruginosa (16.8\%), P. mirabilis $(15.7 \%)$, K. pneumoniae $(14.4 \%)$, E. coli $(8.3 \%)$ and $P$. vulgaris $(6.3 \%)$. 


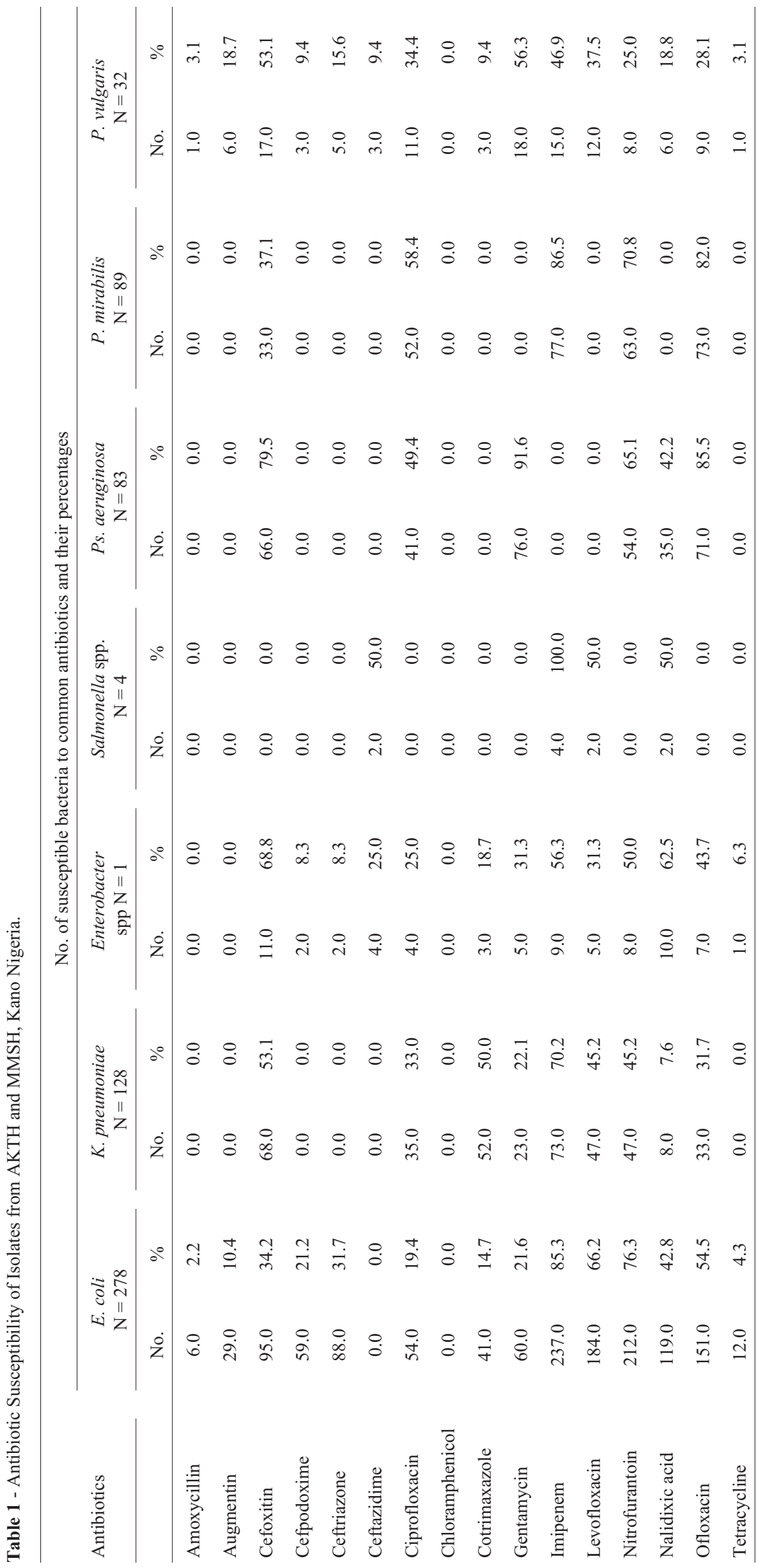


Table 2 - Prevalence of ESBL, AmpC and carbapenemase producers among Gram negative clinical isolates.

\begin{tabular}{|c|c|c|c|c|c|c|c|}
\hline \multirow[t]{2}{*}{$\mathrm{S} / \mathrm{N}$} & \multirow[t]{2}{*}{ Bacterial species } & \multirow{2}{*}{$\begin{array}{l}\text { No. of isolates } \\
\text { screened }\end{array}$} & \multirow{2}{*}{$\frac{\text { ESBL }}{\text { No positive }(\%)}$} & \multicolumn{2}{|c|}{ AmpC } & \multicolumn{2}{|c|}{ carbapenemase } \\
\hline & & & & $\begin{array}{l}\text { No. resistant to } \\
\text { cefoxitin (\%) }\end{array}$ & $\begin{array}{c}\text { Positive AmP C } \\
(\%)\end{array}$ & $\begin{array}{l}\text { No. resistant to } \\
\text { Meropenem (zone }<21 \\
\text { mm in diameter) }\end{array}$ & $\begin{array}{l}\text { Positive carba- } \\
\text { penemase (\%) }\end{array}$ \\
\hline 1 & E. coli & 278 & 47 (17.0) & $95(34)$ & $23(8.3)$ & 187 & $32(11.5)$ \\
\hline 2 & P. mirabilis & 89 & $12(13.5)$ & $33(37)$ & $14(15.7)$ & 22 & $15(16)$ \\
\hline 3 & P. vulgaris & 32 & $2(6.3)$ & $17(53)$ & $2(6.3)$ & 12 & $0(0)$ \\
\hline 4 & Ps. aeruginosa & 83 & $4(4.8)$ & $66(79.6)$ & $14(16.8)$ & 13 & $11(13.3)$ \\
\hline 5 & Enterobacter spp & 16 & $5(31.3)$ & $11(68.7)$ & $3(18.8)$ & 4 & $0(0)$ \\
\hline \multirow[t]{2}{*}{6} & K. pneumoniae & 128 & $19(14.8)$ & $68(53)$ & $19(14.8)$ & 57 & $17(13.3)$ \\
\hline & Total & 626 & $89(14.2)$ & $290(46.3)$ & 75 (11.9) & $295(47.1)$ & 75 (11.9) \\
\hline
\end{tabular}

Note: figures in parenthesis are percentages.

Among the AmpC producers, $57.1 \%$ showed indentation (high production of AmpC enzyme) while 42.1\% showed flattening (low production of AmpC enzyme) (Table 3).

In addition to plasmid mediated AmpC $\beta$-lactamase, the chromosomal expressions of the AmpC among the plasmid mediated strains were investigated. Out of the 77 AmpC producing isolates, inducible AmpC $\beta$-lactamase was detected in $6(7.8 \%)$. Highest was recorded among the Ps. aeruginosa (26.7\%), P. mirabilis (3.2\%).

Furthermore, sixty five out of the six hundred and thirty three isolates $(10.3 \%)$ produces carbapenemase. The highest prevalence of carbapenemase producers was in Proteus mirabilis $(16.0 \%)$, then Ps. aeruginosa, K. pneumoniae (13.3\% each) and E. coli (11.5\%) (Table 2).

Majority of the carbapenemase producers produces MBLs (85.5\%) a type carbapenemase requiring $\mathrm{Zn}+$ for activity (Sinha et al., 2008).

\section{Co-Production of ESBL, AmpC, MBL and carbapenemase}

The co-production of carbapenemase, MBL AmpC and ESBL was also observed among the isolates. Various combinations of different types of enzymes were found particularly in E. coli and K. pneumoniae (Table 4).

\section{Discussions}

The distribution of antibiotic resistance to $\beta$-lactams in our study was very similar to that described by Stéphane et al. (2003) with nearly all of the isolates being resistant or slightly susceptible to commonly prescribed antibiotics in the two hospitals, and many of the isolates showing a decreased susceptibility or resistance to promising antibiotics such as imipenem, levofloxaxin, cefoxitin, cefpodoxime and ceftriaxone (Table 1). This could be linked to the uncontrolled consumption of antimicrobials in Kano such as underuse through lack of access, inadequate dosing, poor adherence, widespread of substandard antibiotics and sales of antibiotics in open markets play an important role. Inappropriate consumption of antimicrobials in Kano may be stimulated by marketing practices such as direct-to-con-

Table 3 - Confirmation of Amp C $\beta$-lactamases (Amp C disc test).

\begin{tabular}{lccccc}
\hline S/N & Bacterial species & No of isolates screened & Positive AmpC & No distortion \\
& & 95 & 14 & 10 & 71 \\
1 & E. coli & 33 & 9 & 5 & 39 \\
2 & P. mirabilis & 17 & 0 & 2 & 15 \\
3 & P. vulgaris & 66 & 6 & 8 & 52 \\
4 & Ps. aeruginosa & 2 & 1 & 0 & 1 \\
5 & M. morganii & 11 & 1 & 2 & 8 \\
5 & Enterobacter spp & 68 & 13 & 6 & 49 \\
6 & K. pneumoniae & 290 & $44(57.1)$ & $33(43.4)$ & 235 \\
\end{tabular}

Note figures in parenthesis are percentages. 
Table 4 - Co-existence of ESBLs, AmpC, MBL and Carbapenemase.

\begin{tabular}{lcccccccc}
\hline Bacterial species & AmpC & ESBL & Carb & Carb + MBL & AmpC + Esbl & ESBL+Carb & AmpC + Carb & ESBL + AmpC + Carb \\
\hline E. coli & 23 & 47 & 22 & 19 & 4 & 3 & 2 & 1 \\
P. mirabilis & 14 & 12 & 15 & 12 & 2 & 0 & 0 & 0 \\
P. vulgaris & 2 & 2 & 0 & 0 & 0 & 0 & 0 & 1 \\
Ps. aeruginosa & 14 & 4 & 11 & 6 & 0 & 0 & 0 & 0 \\
Enterobacter spp & 3 & 5 & 0 & 0 & 9 & 1 & 0 & 1 \\
K. pneumoniae & 19 & 19 & 17 & 9 & 46 & 4 & 5 & 3 \\
Total & 75 & 89 & 65 & 46 & 12 & 0 & \\
\hline
\end{tabular}

sumer advertising which allows pharmaceutical companies to market medicines directly to the public via television, radio, print media, and the internet.

High prevalence of ESBL, AmpC and carbapenemase among the clinical bacterial isolates in the two major hospitals has negative health implications. The prevalence of ESBL is high when compared with the findings of Yushau et al. (2007) who first reported 9.3\% prevalence in Kano, Nigeria in 2007. From then, higher reports of these enzymes among clinical isolates in Kano have been made even among the immune-compromised patients such as tuberculosis and cancer patients (Eyitayo et al., 2009; Yusuf et al., 2011). The high prevalence of ESBL among Enterobacter spp, E. coli and K. pneumoniae in this study is of clinical important as these species are among the most frequent Gram-negative bacteria involved in hospitalacquired infections and nosocomial outbreaks in Kano, Nigeria. Reports of ESBL in Enterobacter in Nigeria is not new, as it spread across the geo political zones of the country. For instance, Aibinu et al. (2003) recorded $20 \%$ in Lagos South West-Nigeria and Akujobi and Ewuru (2010), in Nnewi, Anambra, South East Nigeria.

Initially is was ESBL that was suspicious to be responsible for $\beta$-lactam resistance among our isolates from their initial reports in 2007 among some of their isolates, but due to (i) increased rates of resistance to cefpodoxime, ceftriaxone, ceftazidime in association with clavulanate (ii) decreased susceptibility or resistance to cefoxitin and/or carbapenem, plasmid/chromosomal mediated AmpC $\beta$-lactamases and carbapenemase were thought to pose new clinical threat because these enzymes confer resistance to cephamycins and they are not affected by $\beta$-lactamase inhibitors, and can, in strains with loss of outer membrane porins, provide resistance to carbapenems. In view of the above, the isolates were further screened for other beta lactamase enzymes such as AmpC and carbapenemase beta lactamases.

The prevalence of AmpC production was 11.9\%. This prevalence rate is higher than that reported from some parts of the world. For instance, Singhal et al. (2005) reported $8 \%$ in India, Eyitayo et al. (2009) however reported a higher prevalence $(23 \%)$ in Lagos-Nigeria among cancer patients.

Phenotypic detection of AmpC in E. coli as used in this study does not indicate if the enzyme is chromosomal or plasmid mediated. Chromosomal AmpC $\beta$-lactamase was not detected in $E$. coli in this study meaning that plasmid mediated $\mathrm{AmpC}$ which are faster to spread to other bacteria are the cause of their wide spread in the hospitals. Initially, moderate resistance of some of the isolates to multiple drugs was used to suggest a chromosomal AmpC (Kenneth, 2010), and resistance to multiple drugs shown my most of the $E$. coli is suggestive of plasmid-mediated AmpC production, but even the moderately resistant ones showed no chromosomal expression.

Out of the 291 (46\%) of the isolates showing resistance to cefoxitin in the present study, only $76(26.1 \%)$ were AmpC producers. Cefoxitin resistance in this type of $\mathrm{AmpC}$ negative isolates could be due to a decreased permeability of porins (Clark, 1996; Lee et al., 2003).

Carbapenemase-producing isolates have not been described to date in Nigeria. Here, we report the emergence of carbapenemase producing clinical isolates in two major hospitals in Kano, Nigeria. Although, carbapenem usage in Kano, Nigeria is low because of their cost. The origin or source of these carbapenemase-producing isolates is unknown, but genotypic studies of the isolates could answer questions about whether the strains were imported or they emerged locally and spread by gene transfer. This is because one of the patients from AKTH has a history of travel to India for treatment. Equally important is that patients from MMSH are usually being referred to AKTH when their conditions deteriorate, this will facilitate their spread to other hospitals. The MHT used for carbapenemase confirmation in the study does not distinguish between carbapenemase types and lacks sensitivity for MBLs detection (Lee et al., 2003). Specific MBLs confirmatory test involving EDTA (chelating agent) was used (Walsh et al., 2005).

The total resistance of $P$. aeruginosa to imipenem raise suspicious of carbapenemase production initially as carbapenemase-producing $P$. aeruginosa strains is known to exhibit reduced susceptibility to imipenem (Queenan and Bush, 2007). In addition, some after showing negative 
ESBL and AmpC, but still showed reduced or no sensitivity to carbapenem, this also raises suspicious of MBLs production from the isolates. The detection of carbapenemase and MBLs type among the isolates from the hospitals is dangerous for hospitals that lack information of their existence talk less of their detection and if result in nosocomial outbreaks can be disastrous to the hospital and the community at large. Carbapenem resistance in non carbapenemase producing strains as observed may be as a result of modifications in outer membrane proteins (Clark, 1996) or penicillin-binding proteins (Fernando et al., 2009).

Mechanisms of resistance to $\beta$-lactam by producing ESBL, AmpC and carbapenemase were also noticed as some of the isolates produce different combinations of the enzymes. Similar co-production of enzymes have been reported by different researchers. For instance, Sinha et al. (2008) reported 8\% co-existence in E. coli. A prevalence of $1.25 \%$ (1/80) was demonstrated by Mathur et al. (2002) among $E$. coli in India. These co-productions among some isolates as observed in this study is indicative of the existence of multi-drug resistant bacteria pathogens which may be responsible for treatment failure and/or outbreaks of infections caused by resistant organisms. Longer hospital stays as often observed in the hospitals and resulting higher treatment costs as well as disease complications are other likely consequences of these co-productions of enzymes. Interestingly, 4 of the E. coli and 2 of the P. aeruginosa of totally resistant isolates were found to produce all the three enzymes. However, 2 out of the remaining $E$. coli produced AmpC and carbapenemase together and $1 \mathrm{~K}$. pneumoniae produces ESBL and carbapenemase after repeated experiment. This may result in their associated resistance to aminoglycosides and trimethoprin sulfamethotazole, as well as high frequency of fluroquinolone resistance because many bacteria carrying genes for AmpC, ESBL or carbapenemase production on their plasmids may also carry genes responsible for resistance to other non $\beta$-lactam antibiotics (Mathur et al., 2002).

\section{Conclusion}

From the findings of the study the following conclusions were drawn:

- Antibiotic resistance among isolates from the two hospitals increases at an alarming.

- Resistance to cephamycins, carbapenems are on increase despite their low availability and low prescriptions.

- Carbapenemase, AmpC and Extended spectrum $\beta$-lactamases are believe to be major cause of $\beta$-lactam resistance in the two hospitals

- Co-production of two or more of the enzymes occurred among some of the isolates raising fears of resistance to a multitude of antibiotics in the treatment of clinical infections.

\section{Acknowledgments}

We are indebted to Dr Nasiru Magaji of the Microbiology Department, Aminu Kano Teaching Hospital, Kano-Nigeria for providing the control strain and logistics for the smooth conduct of the research. We also wish to thank University research Grant Committee, Bayero University, Kano-Nigeria for providing the fund.

\section{References}

Aibinu I, Odugbemi P, Brian JM (2003) Extended-spectrum $\beta$-lactamases in isolates of Klebsiella spp and Escherichia coli from Lagos. Nig J Health Biomed Sci 2:53-60.

Akujobi CN, Ewuru CP (2010) Detection of extended spectrum $\beta$-lactamases in Gram negative bacilli from clinical specimens in a teaching hospital in South eastern Nigeria. Niger Med J 51:141-146.

Anderson KF, Lonsway DR, Rasheed JK, Biddle J, Jensen B, McDougal LK (2007) Evaluation of methods to identify the Klebsiella pneumoniae carbapenemase in Enterobacteriaceae. J Clin Microbiol 45:2723-2725.

Arakawa Y, Shibata N, Shibayama K, Kurokawa H, Yagi T, Fujiwara H (2000) Convenient test for screening metallo- $\beta$-lactamase-producing gram-negative bacteria by using thiol compounds. J Clin Microbiol 38:40-43.

Black JA, Moland ES, Thomson KC (2005) AmpC disk test for detection of plasmid-mediated AmpC $\beta$-lactamases in Enterobacteriaceae lacking chromosomal AmpC $\beta$-lactamases. J Clin Microbiol 43:3110-3113.

Bush K, Jacoby GA, Medeiros AA (1995) A functional classification scheme for $\beta$-lactamases and its correlation with molecular structure. Antimicrob Agents Chemother 39:12111233.

Clark RB (1996) Imipenem resistance among Acinetobacter baumannii: Association with reduced expression of a 33-36 $\mathrm{kDa}$ outer membrane protein. Journal of Antimicrobial Chemotherapy 38:245-251.

Clinical Laboratory Standards Institute (CLSI) (2005) Performance standards for antimicrobial disk susceptibility test. 8th ed. Approved standards, M2-A8, Wayne, Pa, USA.

Emery CL, Weymouth LA (1997) Detection and clinical significance of extended-spectrum $\beta$-lactamases in a tertiary-care medical center" J Clin Microbiol 35:2061-2067.

Eyitayo O, Adenipekun I, Aibinu E, Oluwole D, Afolabi A, Aderemi T (2009) Occurrence of $\beta$-lactamase resistance among isolates from cancer patients in Lagos, Nigeria. Academia Arena 1(5):1553-992.

Fernando P, Tania M, Leonor G, Melina R, Alejandra C (2009) Sensitive Screening Tests for Suspected Class A Carbapenemase Production in Species of Enterobacteriaceae. J Clin Microbiol 47(6):1631-1639.

Kenneth ST (2010) Extended-Spectrum- $\beta$-Lactamase, AmpC, and Carbapenemase issues. J Clin Microbiol 48(4):10191025.

Lee K, Lim YS, Yong D, Yum JH, Chong Y (2003) Evaluation of the Hodge test and the imipenem-EDTA double-disk synergy test for differentiating metallo-beta-lactamaseproducing isolates of Pseudomonas spp. and Acinetobacter spp. J Clin Microbiol 41:4623-4629. 
Livermore DM, Woodford N (2000) Carbapenemases a problem in waiting? Current Opinion in Microbiology 3 (5):489-495.

Mathur P, Kapil A, Das B, Dhawan B (2002) Prevalence of ESBL producing Gram negative bacteria in a tertiary care hospital. India J Med Res 115:153-157.

Naumorskil L, Palzkill T (1999) Outbreak of ceftazidime resistance due to moral extended spectrum $\beta$-lactamases in isolates from cancer patients. Antimicrob agents chemother 36(4):91-95.

Paterson DL, WC KO, Goossens H (2004) Antibiotic therapy for Klebsiella pneumoniae bacteremia. Implication of production of Extended spectrum $\beta$ - Lactamases. J Clin Microbiol 39(5):50-57.

Queenan AM, Bush K (2007). Carbapenemases: The versatile beta-lactamases. Clin Microbiol Rev 20:440-458.

Sanders WE, Tenney JH, Kessler RE (1996) Efficacy of cefepime in the treatment of infections due to multiply resistant Enterobacter species. Clin Infect Dis 23:454-461.

Singhal S, Mathur T, Khan S, Upadhyay DJ, Chugh S, Gaind R (2005) Evaluation of Methods for AmpC $\beta$-Lactamase in Gram Negative Clinical Isolates from Tertiary Care Hospitals. Indian J Med Microbiol 23:120-124.

Sinha P, Rajni S, Suman R, Raman S, Smita S, Deepali P (2008) Prevalence of extended spectrum $\beta$ - lactamase and AmpC $\beta$ lactamase producers among $E$. coli isolates in a tertiary care hospital in jaipur. Indian $\mathrm{J}$ of pathol and Microbiol 51(3):367-369.

Stéphane C, Nathalie C, Eric E, Cécile G, Henri D, Alain R (2003) AmpC cephalosporinase hyperproduction in Acinetobacter baumannii clinical strains. J Antimicrob Chemother 52(4):629-635.

Walsh TR, Toleman MA, Poirel L, Nordmann P (2005) Metallobeta-lactamases: The quiet before the storm? Clin Microbiol Rev 18:306-325.

Winokur PL, Brueggemann-Desalvo DL (2005) Animal and human multidrug-resistant cephalosporin-resistant Salmonella isolates expressing a plasmid-mediated CMY-2, AMP-C $\beta$-lactamases. Antimicrob Agents Chemother 44:27772783.

Yusha'u M, Olonitola SO, Aliyu BS (2007) Prevalence of Extended-Spectrum $\beta$ - lactamases (ESBLs) among members of the Enterobacteriaceae isolates obtained from Mohammed Abdullahi Wase Specialist Hospital, Kano, Nigeria. Internl J Pure and App Sci 1(3):42-48.

Yusuf I, Arzai AH, Umar A, Magaji N, Salisu N, Tukur A, Hamid KM, Haruna M (2011) Prevalence of Extended Spectrum $\beta$ Lactamases (ESBL) producing Escherichia coli and Klebsiella pneumoniae in Tuberculosis patients in Kano, Nigeria. Bayero J of Pure App Sci 4(2):182-185.

All the content of the journal, except where otherwise noted, is licensed under a Creative Commons License CC BY-NC. 